\title{
Pathological features of hypertrophic obstructive cardiomyopathy
}

\author{
M. J. DAVIES, ARIELA POMERANCE 1 , AND R. D. TEARE \\ From the Departments of Histopathology and Forensic Medicine, St George's Hospital Medical School, \\ London, and the Department of Histopathology, Northwick Park Hospital, Harrow
}

SYNOPSIS The macroscopic features of hypertrophic obstructive cardiomyopathy are variable. The most easily recognized picture is of disproportionate and asymmetrical left ventricular hypertrophy with a small ventricular volume. Symmetrical ventricular hypertrophy also occurs and dilatation of the ventricular cavity may lead to a configuration more usually associated with congestive cardiomyopathy. Papillary muscle involvement leads to a bullet shape, often retained even when the ventricle dilates. Eighteen of the hearts showed a distinctive band of fibrous thickening below the aortic valve. This was a mirror image of the free edge of the anterior mitral cusp, had the microscopic features of an endocardial friction lesion, and was clearly the morphological expression of the systolic contact between cusp and septum seen on cineangiography. This band is characteristic of hypertrophic obstructive cardiomyopathy; it was more common in older patients and is of particular diagnostic value in cases with symmetrical hypertrophy, including those with dilated ventricular cavities.

Sudden death was the commonest presentation in the younger cases but in several cases over 60 years at death hypertrophic obstructive cardiomyopathy was an incidental necropsy finding.

Following Teare's (1958) report of eight young adults with tumour-like asymmetrical hypertrophy of the heart, a large literature on hypertrophic obstructive cardiomyopathy has accumulated. Most studies have been clinically orientated and less attention has been paid to the morphological aspects of this condition.

Many pathologists will be familiar with the easily recognized asymmetrical hypertrophy seen in young and early middle-aged subjects, usually associated with sudden death. It is, however, not generally appreciated that hypertrophic obstructive cardiomyopathy is not necessarily asymmetrical or fatal or that it also occurs in older subjects. We have recently reviewed the pathology of 47 hearts with this feature and the present paper describes our findings, emphasizing those macroscopic features which are of diagnostic value in hearts where the hypertrophy is not of the easily recognized asymmetrical, septal type.

\section{Material}

The diagnosis of hypertrophic obstructive cardiomyopathy was initially made on clinical history and

In recejpt of a grant from the British Heart Foundation.

Received for publication 27 March 1974. naked-eye examination, confirmed by histological study of many areas throughout the heart. Microscopy showed thick, abnormally branched myofibres, disorganized architecture, fibrosis, and whorl formation which are characteristic of the condition (Pare, 1961; Olsen, 1971; Van Noorden, Olsen, and Pearse, 1971; Olsen, 1972). These foci were, however, often present in only some of the many blocks examined. The problem of histological interpretation in hypertrophic obstructive cardiomyopathy has recently been comprehensively reviewed by Olsen and others (Olsen, 1971; Van Noorden et al, 1971; Olsen, 1972) but when the whole heart from which multiple blocks can be taken is available diagnosis is rarely difficult.

A clinical diagnosis of hypertrophic obstructive cardiomyopathy had been made in 13 cases, up to 11 years before death, and three cases were known to be familial. Three patients died shortly after myomectomy to relieve left ventricular outflow obstruction.

\section{Findings}

AGE AND SEX DISTRIBUTION (FIG 1)

Ages ranged from 13 to 87 years and 34 of the 
patients were men. Fourteen $(30 \%)$ of the 47 patients were over 60 years old at death and six $(13 \%)$ over 70 years.

\section{PRESENTATION}

In the series as a whole this was most often as sudden death (see table). Nine patients had presented with congestive cardiac failure and in six patients, all over 60 years, hypertrophic obstructive cardiomyopathy was an unexpected incidental postmortem finding. Five of these six patients had died of malignant disease (see table).

\begin{tabular}{|c|c|c|c|c|c|c|c|c|c|c|}
\hline \multirow{2}{*}{$\begin{array}{l}\text { Case } \\
\text { No. }\end{array}$} & \multicolumn{4}{|c|}{ Clinical Features } & \multicolumn{6}{|c|}{ Pathological Features } \\
\hline & Age & Sex & Cause of Death & $\boldsymbol{B P}$ & $\begin{array}{l}\text { Total } \\
\text { Heart } \\
\text { Weight }\end{array}$ & $\begin{array}{l}\text { LV } \\
\text { Weight }\end{array}$ & $\begin{array}{l}\text { RV } \\
\text { Weight }\end{array}$ & $\begin{array}{l}\text { LV } \\
\text { Hyper- } \\
\text { trophy }\end{array}$ & $\begin{array}{l}\text { Subaortic } \\
\text { Bar }\end{array}$ & $\begin{array}{l}\text { LV } \\
\text { Cavity }\end{array}$ \\
\hline 1 & 20 & $\mathbf{M}$ & U sudden death & - & 504 & 360 & 104 & $\mathbf{A}$ & 0 & $\mathbf{S}$ \\
\hline 2 & 13 & $\mathbf{M}$ & U sudden death & - & 180 & 110 & 25 & $\mathbf{A}$ & $\mathbf{0}$ & $\mathbf{S}$ \\
\hline 3 & 23 & $\mathbf{M}$ & U sudden death & - & 470 & 290 & 48 & $\mathbf{A}$ & 0 & $\mathbf{N}$ \\
\hline 4 & 54 & $\mathbf{M}$ & U sudden death & 一 & 470 & 265 & 34 & $\mathbf{A}$ & 0 & $\mathbf{N}$ \\
\hline 5 & 24 & $\mathbf{M}$ & U sudden death & - & 510 & 340 & 70 & $\mathbf{S}$ & + & $\mathbf{N}$ \\
\hline 6 & 54 & $\mathbf{F}$ & D 6 yr, operative death & $130 / 80$ & 440 & 298 & 80 & $\mathbf{S}$ & + & $\mathbf{N}$ \\
\hline 7 & 14 & $\mathbf{M}$ & U sudden death & - & 300 & 194 & 34 & $\mathbf{A}$ & 0 & $\mathbf{N}$ \\
\hline 8 & 52 & $\mathbf{M}$ & U sudden death & - & 688 & 490 & 75 & $\mathbf{S}$ & + & $\mathbf{L}$ \\
\hline 9 & 48 & $\mathbf{M}$ & U sudden death & - & 690 & 480 & 45 & $\mathbf{S}$ & 0 & $\mathbf{N}$ \\
\hline 10 & 48 & $\mathbf{F}$ & D 6 yr, CCF & $110 / 70$ & 480 & 310 & 44 & $\mathbf{A}$ & 0 & $\mathbf{L}$ \\
\hline 11 & 67 & $\mathbf{M}$ & $\mathrm{CF}$, carcinoma bladder & $170 / 90$ & 450 & 260 & 36 & $\mathbf{A}$ & $\mathbf{0}$ & $\mathbf{N}$ \\
\hline 12 & 47 & $\mathbf{M}$ & D 5 yr, operative death & $130 / 70$ & 420 & 270 & 40 & $\mathbf{A}$ & $\mathbf{0}$ & $\mathbf{S}$ \\
\hline 13 & 24 & $\mathbf{M}$ & D sudden death & $140 / 95$ & 580 & 380 & 88 & $\mathbf{A}$ & + & $\mathbf{N}$ \\
\hline 14 & 36 & $\mathbf{M}$ & U sudden death & - & 530 & 350 & 64 & $\mathbf{A}$ & + & $\mathbf{S}$ \\
\hline 15 & 49 & $\mathbf{F}$ & $\mathrm{U}$ sudden death & - & 390 & 235 & 41 & $\mathbf{A}$ & 0 & $\mathbf{N}$ \\
\hline 16 & 47 & $\mathbf{M}$ & D, FH sudden death & $110 / 60$ & 500 & 305 & 75 & $\mathbf{A}$ & 0 & $\mathbf{S}$ \\
\hline 17 & 51 & $\mathbf{M}$ & D $4 \mathrm{yr}$, sudden death & $170 / 110$ & 450 & 250 & 43 & $\mathbf{A}$ & 0 & $\mathbf{S}$ \\
\hline 18 & 56 & $\mathbf{M}$ & U sudden death & - & 390 & 260 & 41 & $\mathbf{A}$ & 0 & $\mathbf{S}$ \\
\hline 19 & 19 & $\mathbf{M}$ & U sudden death & 一 & 210 & 115 & 34 & $\mathbf{A}$ & $\mathbf{0}$ & $\mathbf{S}$ \\
\hline 20 & 56 & $\mathbf{M}$ & U sudden death & 一 & 485 & 305 & 80 & $\mathbf{A}$ & 0 & $\mathbf{S}$ \\
\hline 21 & 61 & $\mathbf{M}$ & U sudden death & 一 & 340 & 195 & 60 & $\mathbf{S}$ & + & $\mathbf{S}$ \\
\hline 22 & 47 & $\mathbf{M}$ & U sudden death & - & 370 & 205 & 71 & $\mathbf{A}$ & 0 & $\mathbf{S}$ \\
\hline 23 & 38 & $\mathbf{M}$ & $\begin{array}{l}\text { D } 6 \text { yr, CCF/angina } \\
\text { operative death }\end{array}$ & $110 / 60$ & 350 & 240 & 53 & $\mathbf{A}$ & 0 & $\mathbf{L}$ \\
\hline 24 & 41 & $\mathbf{M}$ & U sudden death & - & 570 & 370 & 44 & $\mathbf{A}$ & $\mathbf{0}$ & $\mathbf{S}$ \\
\hline 25 & 29 & $\mathbf{M}$ & U sudden death & - & 430 & 240 & 71 & $\mathbf{A}$ & $\mathbf{0}$ & $\mathbf{N}$ \\
\hline 26 & 65 & $\mathbf{M}$ & D 4 yr, CCF & $140 / 70$ & 740 & 460 & 120 & $\mathbf{S}$ & + & $\mathbf{L}$ \\
\hline 27 & 51 & $\mathbf{M}$ & U sudden death & - & 310 & 180 & 40 & $\mathbf{A}$ & 0 & $\mathbf{S}$ \\
\hline 28 & 76 & $\mathbf{M}$ & CF carcinoma bronchus & $180 / 100$ & 275 & 165 & 31 & $\mathbf{A}$ & 0 & $\mathbf{N}$ \\
\hline 29 & 81 & $\mathbf{F}$ & U CCF & $100 / 70$ & 485 & 300 & 85 & $\mathbf{S}$ & + & $\mathbf{N}$ \\
\hline 30 & 66 & $\mathbf{M}$ & U sudden death & - & 610 & 403 & 35 & $\mathbf{A}$ & $\mathbf{0}$ & $\mathbf{S}$ \\
\hline 31 & 26 & $\mathbf{F}$ & D $3 \mathrm{yr}$, FH sudden death & $100 / 60$ & 390 & 200 & 95 & $\mathbf{A}$ & 0 & $\mathbf{S}$ \\
\hline 32 & 14 & $\mathbf{M}$ & D 10 yr, CCF sudden death & $110 / 70$ & 250 & 130 & 88 & $\mathbf{S}$ & $\mathbf{0}$ & $\mathbf{S}$ \\
\hline 33 & 18 & $\mathbf{M}$ & U sudden death & - & 250 & 140 & 35 & $\mathbf{A}$ & 0 & $\mathbf{N}$ \\
\hline 34 & 49 & $\mathbf{M}$ & U CCF sudden death & $130 / 70$ & 608 & 360 & 73 & $\mathbf{S}$ & + & $\mathbf{L}$ \\
\hline 35 & 36 & $\mathbf{F}$ & D 10 yr, FH sudden death & $115 / 75$ & 240 & 125 & 36 & $\mathbf{S}$ & + & $\mathbf{N}$ \\
\hline 36 & 52 & $\mathbf{M}$ & U sudden death & - & 620 & 420 & 110 & $\mathbf{A}$ & 0 & $\mathbf{S}$ \\
\hline 37 & 39 & $\mathbf{F}$ & U sudden death & 一 & 405 & 254 & 31 & $\mathbf{A}$ & 0 & $\mathbf{S}$ \\
\hline 38 & 87 & $\mathbf{F}$ & U CCF & $160 / 100$ & 510 & 370 & 47 & $\mathbf{A}$ & + & $\mathbf{L}$ \\
\hline 39 & 61 & $\mathbf{M}$ & U sudden death & - & 604 & 420 & 43 & $\mathbf{A}$ & $\mathbf{0}$ & $\mathbf{S}$ \\
\hline 40 & 25 & $\mathbf{M}$ & D $11 \mathrm{yr}$, sudden death & $110 / 80$ & & & & $\mathbf{S}$ & 0 & $\mathbf{L}$ \\
\hline 41 & 72 & $\mathbf{F}$ & CF cholecystitis & $150 / 80$ & 535 & $*$ & $*$ & $\mathbf{A}$ & + & $\mathbf{N}$ \\
\hline 42 & 54 & $\mathbf{M}$ & U sudden death & - & 600 & $*$ & $*$ & $\mathbf{S}$ & + & $\mathbf{L}$ \\
\hline 43 & 63 & $\mathbf{F}$ & D $6 \mathrm{yr}$, sudden death & $180 / 95$ & 675 & $*$ & $*$ & $\mathbf{S}$ & + & $\mathbf{L}$ \\
\hline 44 & 61 & $\mathbf{F}$ & U sudden death & - & 700 & $*$ & $*$ & $\mathbf{S}$ & + & $\mathbf{L}$ \\
\hline 45 & 69 & $\mathbf{M}$ & CF carcinoma bronchus & $150 / 90$ & 550 & & & $\mathbf{S}$ & + & $\mathbf{L}$ \\
\hline 46 & 72 & $\mathbf{F}$ & CF carcinoma bronchus & $110 / 70$ & 410 & & & $\mathbf{S}$ & + & $\mathbf{N}$ \\
\hline 47 & 84 & $\mathbf{F}$ & CF carcinoma bladder & 一 & 360 & & & $\mathbf{S}$ & + & $\mathbf{S}$ \\
\hline
\end{tabular}

Table Summary of clinical and pathological data from 47 cases of hypertrophic obstructive cardiomyopathy

$\mathrm{U}=$ undiagnosed clinically but cause of death due to HOCM

$\mathbf{D}=$ diagnosed clinically-time interval before death in years

$\mathbf{C F}=$ coincidental finding at necropsy, unrelated to death

$\mathbf{A}=$ asymmetrical

LV Hypertrophy

$\mathbf{S}=$ symmetrical

$\mathbf{N}=$ normal

LV Cavity

$\mathbf{S}=$ small

$\mathbf{L}=$ large

CCF = congestive cardiac failure

* = specimens retained for museum 


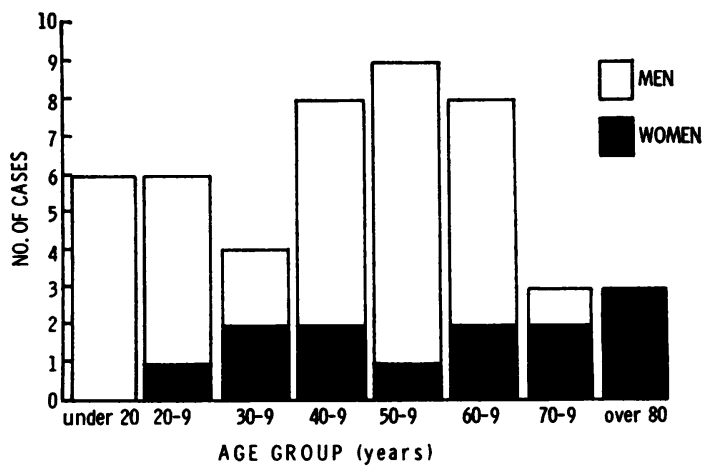

Fig 1 The age and sex distribution of the 47 cases

\section{PATHOLOGY}

The type of muscular hypertrophy varied from classical asymmetrical hypertrophy as described by Teare (1958) (figs 2, 3) to relatively uniform hypertrophy of the entire left ventricle (fig 4). Symmetrical hypertrophy was seen more often in older hearts, two-thirds of which showed marked thickening of the whole left ventricle, while two-thirds of the hearts from cases under 60 years had hypertrophy of the asymmetrical type.

A striking feature of hypertrophic obstructive cardiomyopathy, particularly in hearts from cases over 60 years, was the presence (figs 5 and 8 ) of a band-like endocardial fibrous thickening of the interventricular septum extending for 2 to $4 \mathrm{~cm}$ below the aortic valve. This lesion was characterized

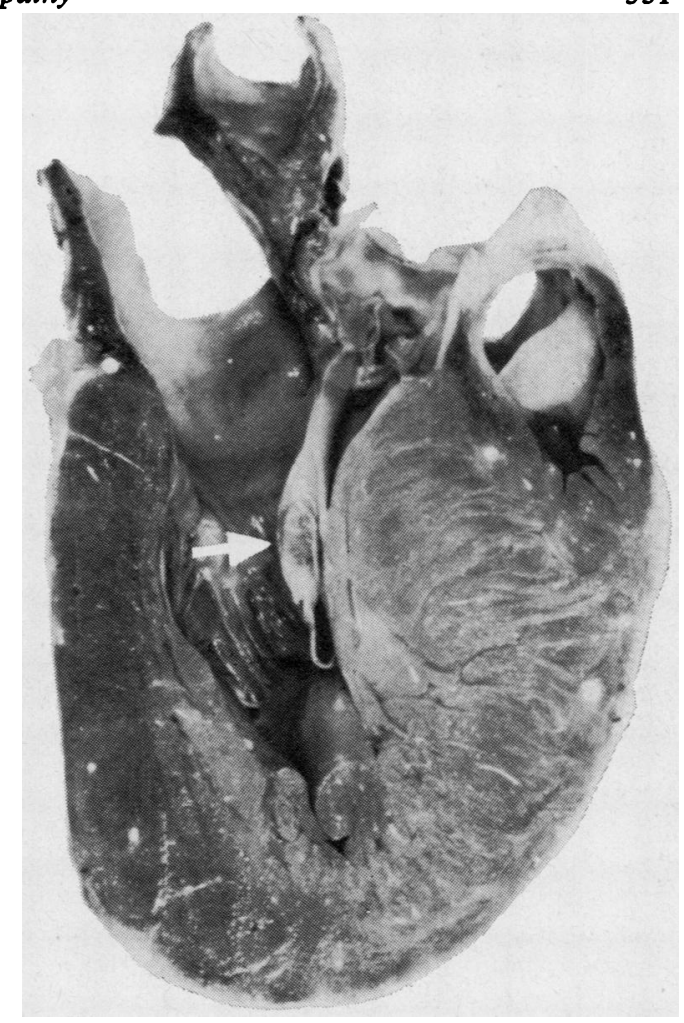

Fig 2 Classical asymmetrical hypertrophy, as described by Teare. Note that the anterior cusp of the mitral valve (arrow) is in contact with the greatly thickened anteroseptal wall of the left ventricle.

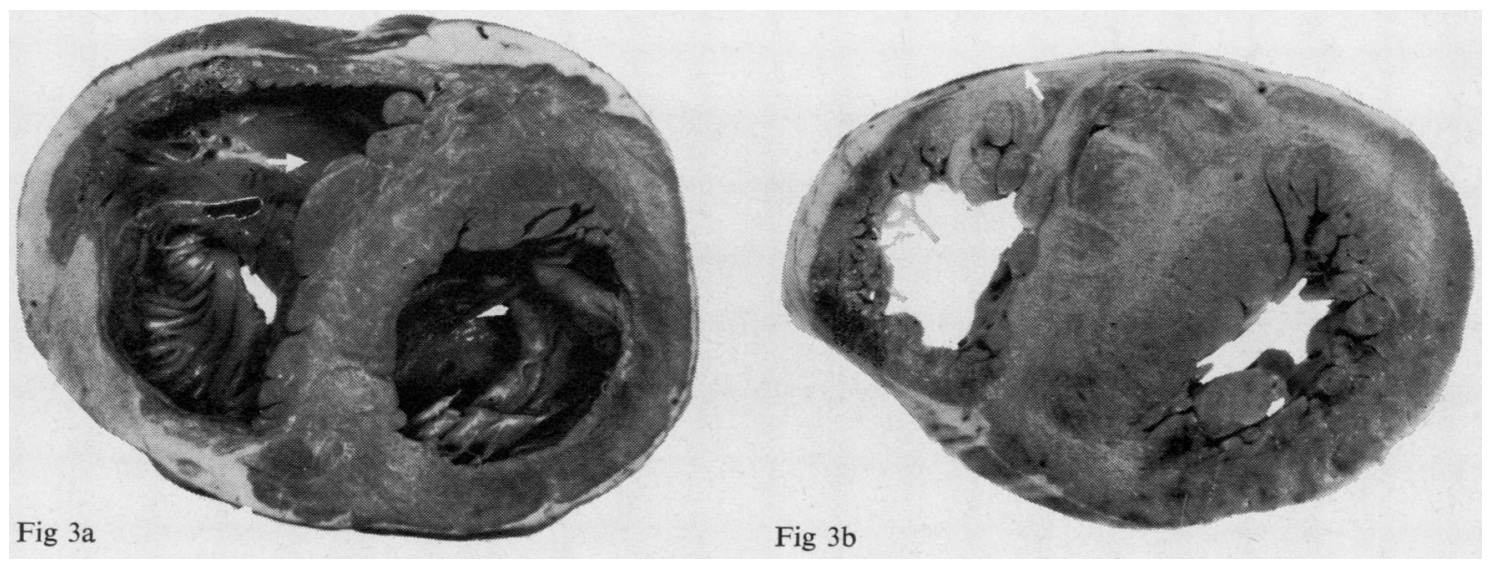

Fig 3 Transverse section of both ventricles showing asymmetrical hypertrophy. In (a) the area of macroscopic abnormality involves the anterior wall of the left ventricle and the anterior half of the septum. Septal muscle encroaches (arrow) on the right ventricular outflow but the free right ventricle is normal. In (b) the area of macroscopic abnormality includes the whole septum, most of the free wall of the left ventricle, and the free wall of the right ventricle anteriorly (arrow). 


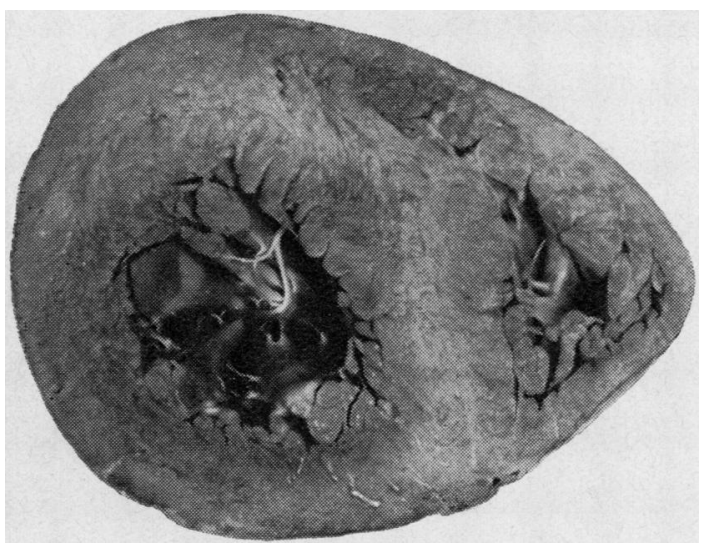

Fig 4 Transverse section of both ventricles showing symmetrical involvement of the entire left ventricle and most of the right ventricle. From a man of 47 with a known clinical diagnosis of hypertrophic obstructive cardiomyopathy who died suddenly. His son had also died suddenly with the same abnormality.

by a well defined lower edge (fig 5), and, on superimposing the anteior mitral cusp on the septum, it was apparent that the configuration of the lower (apical) part of this band was a mirror image of the aortic surface of the lower part of this cusp. A minor degree of flat fibrous thickening was usually also visible on the aortic surface of the anterior mitral cusp (fig 5). These lesions were clearly the result of repeated systolic contact between the free edge of the cusp and the septum. Histology (figs 6 and 7) showed the superficial dense collagenous and elastic thickening of the endocardium characteristic of jet and friction lesions. Total heart weight was usually increased (see table) and assessment of isolated ventricular weights by the Fulton method (Fulton, Hutchinson, and Jones, 1952) showed disproportionate left ventricular hypertrophy to be characteristic (fig 9). Right ventricular mass, on the other hand, varied from normal to grossly increased (table). Asymmetrical hypertrophy may involve a small or large segment of the left ventricle and, when the right ventricle is affected, this involves the right ventricular free wall.

Papillary muscle involvement produces large, blunt-tipped muscle masses with a bullet-like shape. The left ventricular cavity is characteristically small, especially when seen after sudden death, but if death occurs after prolonged cardiac failure the resultant ventricular dilatation produces an appearance akin to congestive cardiomyopathy (fig 10).

Only one of our cases had calcification of the mitral valve ring, an association noted by Tajik, Guiliani, Frye, Davis, McGoon, and Brandenburg (1972) and Krauss, Weisinger, and Glassman (1972). None showed any evidence of congenital displacement of the mitral cusps (Björk, Hultquist, and Lodin, 1961).

\section{Discussion}

It is clear from our pathological material and from recent clinical studies (Penther, Cousteau, Maurice, and Lenegre, 1970; Whiting, Powell, Dinsmore, and Sanders, 1971; Tajik, Assad-Morell, and Guiliani, 1973) that hypertrophic obstructive cardiomyopathy is not confined to the young and middle aged. Fourteen $(30 \%)$ of the 47 hearts we have studied

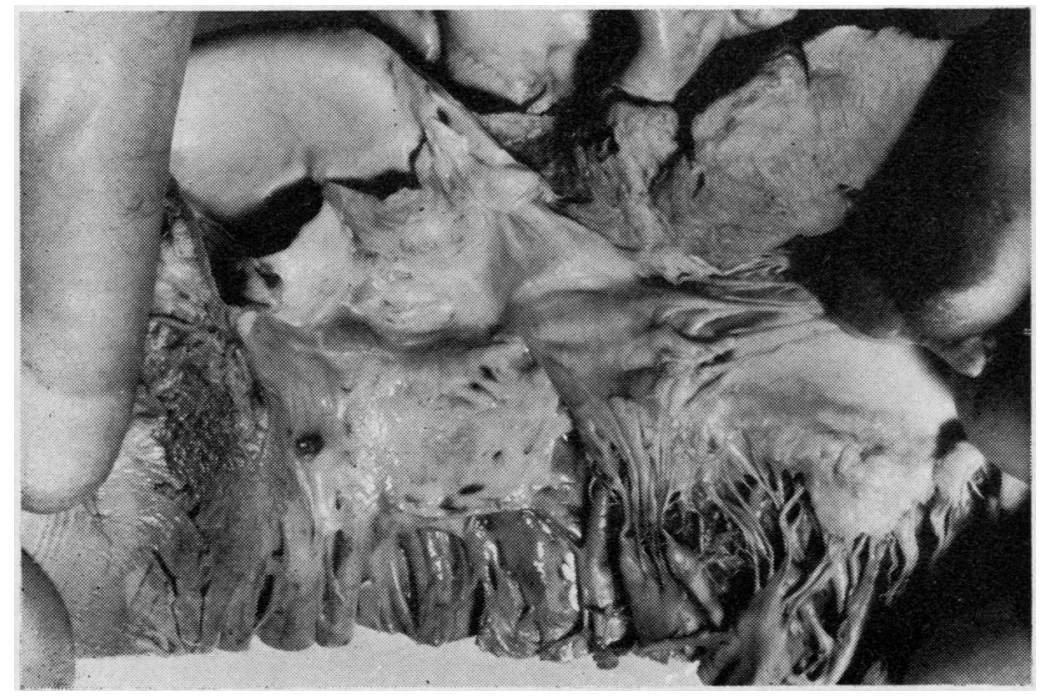

Fig 5 Close-up view of a subaortic band and related anterior mitral valve cusp. The 'mirror image' relationship of the well defined lower edge of the band and the lower part of the aortic surface of the valve cusps can be seen and flat white fibrous thickening is present on the aortic aspect of the distal third of the cusp. From a 36-year-old man who died suddenly. 


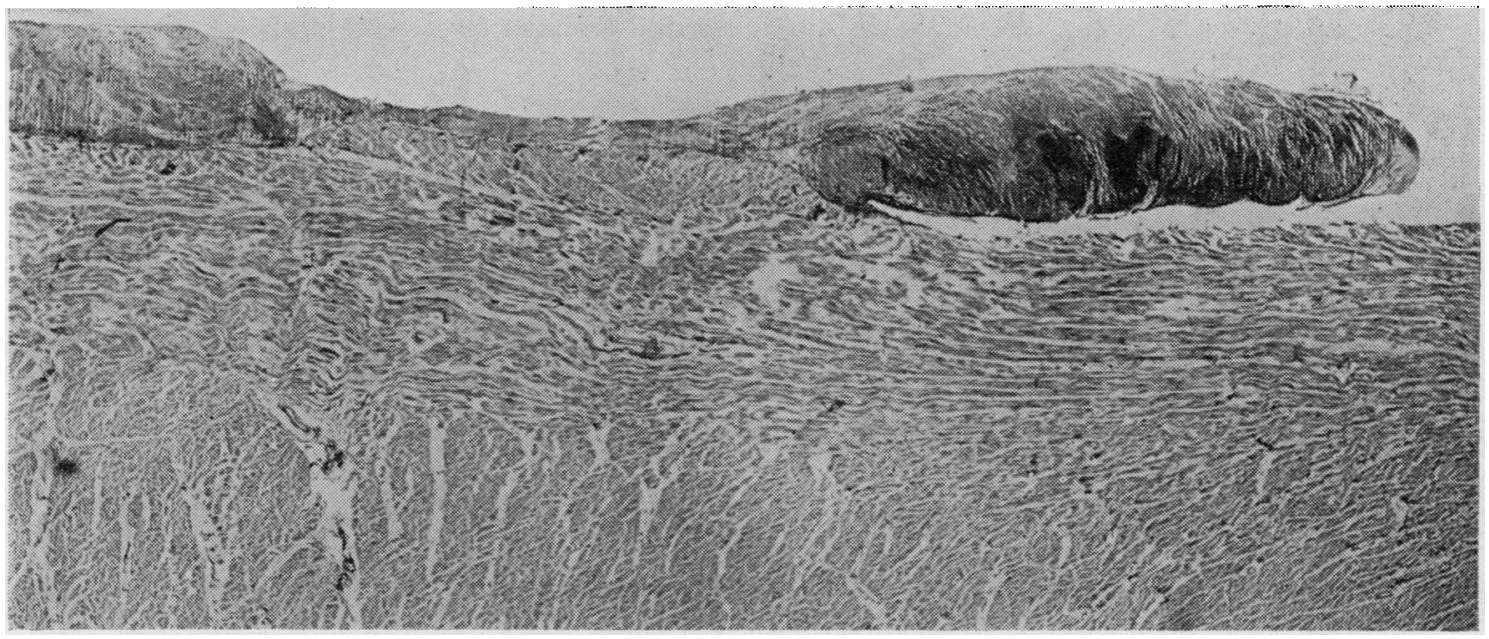

Fig 6 Section through a subaortic band showing the superficial localization of the fibrosis and the valve-like arrangement of dense collagen and endothelialized loose connective tissue which is characteristic of a 'friction' lesion (Weigert's elastic van Geison $\times 14$ ).

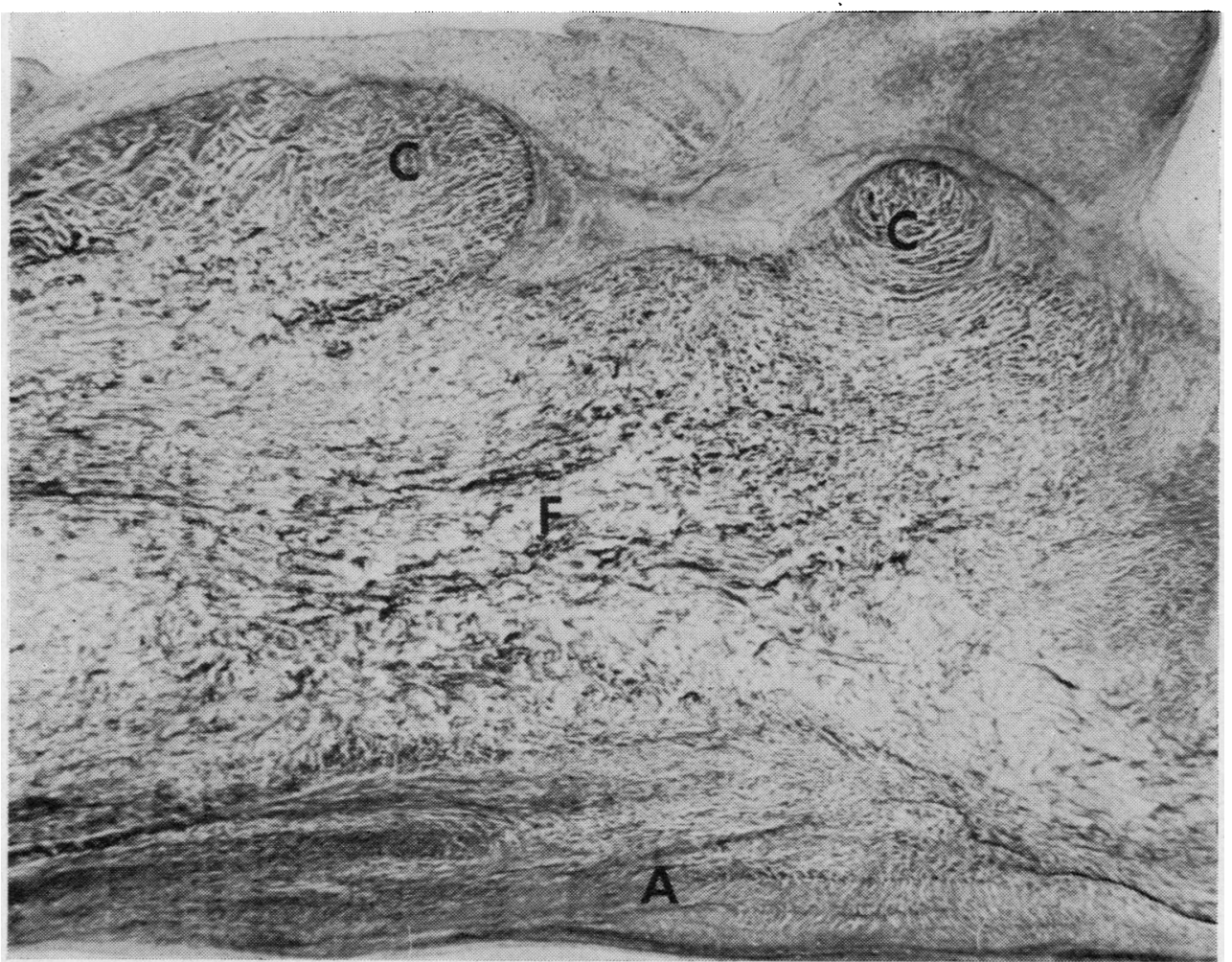

Fig 7 Section through an anterior mitral valve cusp which showed macroscopic thickening as in figure 5. The fibroelastic thickening on the atrial face (A) is normal as is the loose appearance of the fibrosa (F) of the free edge of the cusp but loose connective tissue covers the chordate and intervening endocardium on the aortic face (Weigert's elastic van Geison × 10). 


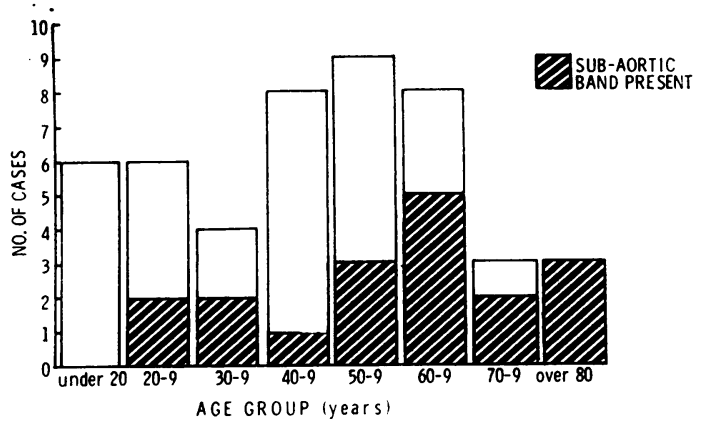

Fig 8 The frequency of the subaortic fibrous band in relation to age.

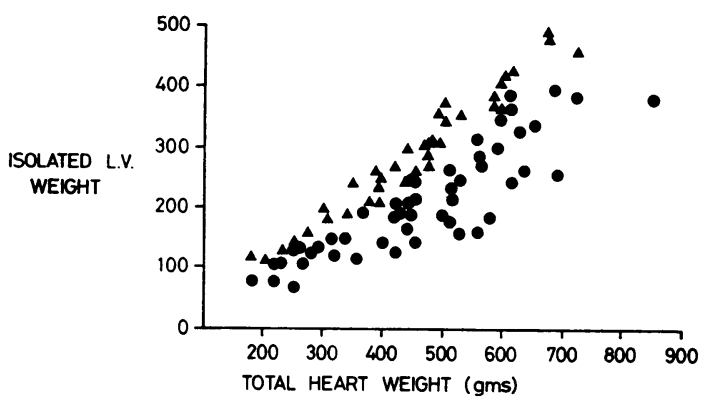

Fig 9 Relation of total heart weight (TW) to isolated left ventricular weight $(L W)$. Triangles refer to cases of hypertrophic obstructive cardiomyopathy, closed circles to normal and hypertensive hearts.

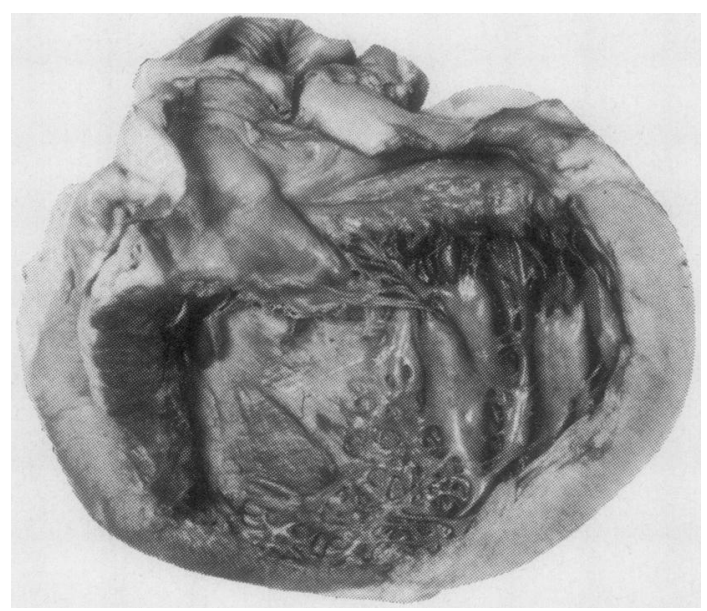

Fig 10 Hypertrophic obstructive cardiomyopathy terminating as cardiac failure. The left ventricle is dilated and globular simulating congestive cardiomyopathy. The papillary muscles are large and blunt. were from cases between 61 and 84 years of age, a similar proportion to that recorded in these clinical series.

A study of the morphological features of the condition in the elderly (Pomerance and Davies, 1974) showed that the hearts from patients over 60 years at death tended to be heavier than those from younger patients, to show more uniform left ventricular hypertrophy, and were more likely to show the distinctive septal subaortic fibrous band.

The presence of subaortic septal endocardial thickening has been briefly noted in several reports and accounts of the pathology of hypertrophic obstructive cardiomyopathy (Brachfield and Gorlin, 1959; Menges, Brandenburg, and Brown, 1961; Stampbach and Senn, 1962; Braunwald, Lambrew, Rockoff, Ross, and Morrow, 1964; Kittle, Reed, and Crockett, 1964; Edwards, 1965;Warkentin and Korns, 1967) but its distinctive features and diagnostic value do not appear to have been recognized. The characteristic feature of this friction lesion is the "mirror image' relation of the well defined lower edge of the septal fibrous band to the aortic surface of the anterior mitral cusp, a relationship which is easily apparent on superimposing the anterior mitral cusp on the related area of the septum and which suggests that the band is the pathological expression of systolic contact between anterior mitral cusp and ventricular septum which is characteristic of hypertrophic obstructive cardiomyopathy in cineangiographic studies (Simon, Ross, and Gault, 1967). The high septal band of hypertrophic obstructive cardiomyopathy is easily distinguished from congenital subaortic stenosis which may also, rarely, be seen in middle and old age (Pomerance and Davies, 1974). In the latter the fibrous or fibromuscular ridge is more protuberant, situated nearer the base of the aortic valve, shows no correspondence with the free edge of the anterior mitral cusp and frequently extends onto the aortic aspect of the cusp itself near its attached border.

The same mechanical factors that produce the septal fibrous lesion are responsible for the mitral cusp thickening also noted in some of the published reports referred to above. This is seen as an irregular, flat, fibrous area on the aortic surface of the distal part of the mitral cusp. It was an inconstant macroscopic finding in our material.

We have emphasized and described in some detail the subaortic band since it is of considerable diagnostic importance for the pathologist. Once formed it remains visible even if the heart dilates and so indicates the correct diagnosis in cases which might otherwise be ascribed to hypertension, ischaemia, or congestive cardiomyopathy'

From our material it is clear that there is a wide 
pathological spectrum of hypertrophic obstructive cardiomyopathy which includes symmetrical hypertrophy with a small ventricular cavity and a dilated hypertrophied left ventricle macroscopically indistinguishable from congestive cardiomyopathy, as well as the familiar and easily recognized asymmetrical form. Diagnostic difficulties are particularly likely to arise in the elderly where the hypertrophy is more likely to be of symmetrical type and hypertrophic obstructive cardiomyopathy is not a condition which is usually considered in this age group.

It is difficult to assess the extent to which personal interests, selection of material, and our early awareness of the diagnostic nature of the subaortic band have been responsible for the high incidence of this finding in our series. However, necropsy observations in 11 of the 133 patients with hypertrophic obstructive cardiomyopathy by Penther and and his colleagues (1970) also reveal a much greater incidence in the older cases. A subaortic band was noted in all six patients dying over 55 years of age but it was present in only one of the five dying under 55 years. A relation to age is to be expected; the fibrous band is simply a form of friction lesion and thus likely to be more prominent in longer standing disease. The higher incidence of symmetrical left ventricular hypertrophy and increased heart weights in the elderly patients is also attributable to a myocardial response to the outflow obstruction and is therefore evidence of longstanding disease.

An interesting and unexpected finding was the number of cases in which hypertrophic obstructive cardiomyopathy was an apparently incidental postmortem finding. All these six patients were elderly, the youngest being 67 years; five died of carcinoma of various primary sites and the sixth of septicaemia associated with cholecystitis. The variability of the clinical course of hypertrophic obstructive cardiomyopathy is well recognized (Frank and Braunwald, 1968; Parker, 1969) and recently echocardiography has shown that asymmetrical septal hypertrophy can be present without any clinical evidence of heart disease (Henry, Clark, and Epstein, 1973). Henry and his colleagues (1973) put forward the concept of a spectrum of hypertrophic obstructive cardiomyopathy and our pathological study supports this suggestion. At one end of the spectrum there are the young patients, often with family histories of hypertrophic obstructive cardiomyopathy or sudden death, who die suddenly and usually show the classical asymmetrical hypertrophy. At the other end are the elderly patients with pathological evidence of longstanding obstruction in the form of subaortic fibrous bands and hypertrophy of the free wall of the left ventricle as well as the septum but who may have had no clinical symptoms of cardiac disease.
We are grateful to Dr K. Misch who contributed three of the six cases obtained from the Stevenage area of Hertfordshire. Dr D. Lamb supplied data on the normal relation of isolated left ventricular weight to total heart weight.

References

Björk, V. O., Hultquist, G., and Lodin, H. (1961). Subaortic stenosis produced by an abnormally placed anterior mitral leaflet. $J$. thorac. cardiovasc. Surg., 41, 659-669.

Brachfeld, N., and Gorlin, R. (1959). Subaortic stenosis: a revised concept of the disease. Medicine (Baltimore), 38, 415-433.

Braunwald, E., Lambrew, C. T., Rockoff, S. D., Ross, J., and Morrow, A. G. (1964). Idiopathic hypertrophic subaortic stenosis. I. A description of the disease based upon an analysis of 64 patients. Circulation, 30, Suppl. IV, 3-119.

Edwards, J. E. (1965). Pathology of left ventricular outflow tract obstruction. Circulation, 31, 586-599.

Frank, S., and Braunwald, E. (1968). Idiopathic hypertrophic subaortic stenosis: clinical analysis of 126 patients with emphasis on the natural history. Circulation, 37, 759-788.

Fulton, R. M., Hutchinson, E. C., and Jones, A. M. (1952). Ventricular weights in cardiac hypertrophy. Brit. Heart J., 14, 413.

Henry, W. L., Clark, C. E., and Epstein, S. E. (1973). Asymmetric septal hypertrophy (ASH): the unifying link in the IHSS disease spectrum: observations regarding its pathogenesis, pathophysiology and course. Circulation, 47, 827-832.

Kittle, C. F., Reed, W. A., and Crockett, J. E. (1964). Infundibulectomy for subaortic hypertrophic stenosis. Circulation, 29, Suppl. I, 119-124.

Krauss, K. R., Weisinger, B., and Glassman, E. (1972). Mitral annular calcification and subaortic stenosis. Circulation, 45, Suppl. II, 178.

Menges, H., Jr., Brandenburg, R. O., and Brown, A. L., Jr. (1961). The clinical hemodynamic and pathologic diagnosis of muscular subvalvular aortic stenosis. Circulation, 24, 1126-1136.

Van Noorden, S., Olsen, E. G. J., and Pearse, A. G. E. (1971). Hypertrophic obstructive cardiomyopathy, a histological histochemical and ultrastructural study of biopsy material, Cardiovasc. Res., 5, 118-131.

Olsen, E. G. J. (1971). Morbid anatomy and histology in hypertrophic obstructive cardiomyopathy. In Hypertrophic Obstructive Cardiomyopathy, edited by G. E. W. Wolstenholme and M. O'Connor (Ciba Foundation Study Group, no. 37), pp. 183-191. Churchill, London.

Olsen, E. G. J. (1972). Pathology of primary cardiomyopathies, Postgrad. Med. J., 48, 732-737.

Pare, J. A. P., Fraser, R. G., Pirozynski, W. J., Shanks, J. A., and Stubington, D. (1961). Hereditary cardiovascular dysplasia : A form of familial cardiomyopathy. Amer. J. Med., 31, 37-62.

Parker, B. M. (1969). The course in idiopathic hypertrophic muscular subaortic stenosis. Ann. intern. Med., 70, 903-911.

Penther, P. Cousteau, J. P., Gay, J., Maurice, P., and Lenegre, J. (1970). Quelques aspects particuliers de la cardiomyopathie obstructive des sumets de plus cinquante-cinq ans (à propos de 14 observations) Arch. Mal. Coeur, 63, 1230-1246.

Pomerance, A. and Davies, M. J. (1974). Pathological features of hypertrophic obstructive cardiomyopathy in the elderly. In preparation.

Simon, A. L., Ross, J., and Gault, J. H. (1967). Angiographic anatomy of the left ventricle and mitral valve in idiopathic hypertrophic subaortic stenosis. Circulation, 36, 852-867.

Stampbach, O., and Senn, A. (1962). Die idiopathische hypertrophische subaortenstenose. Schweiz med. Wschr., 5, 125-130.

Tajik, A. J., Assad-Morrell, J. L., and Guiliani, E. R. (1973). Hypertrophic obstructive cardiomyopathy in the elderly. Amer. Heart J., 85, 574.

Tajik, A. J., Guiliani, E. R., Frye, R. L., Davis, G. D., McGoon, D. C., and Brandenburg, R. O. (1972). Mitral valve and/or annulus calcification associated with idiopathic hypertrophic subaortic stenosis (IHSS). Circulation, 45, Suppl. II, 228.

Teare, D. (1958). Asymmetrical hypertrophy of the heart in young adults. Brit. Heart J., 20, 1-8.

Warkentin, D. L., and Korns, M. E. (1967). Hypertrophic subaortic stenosis in the aged. Amer. Heart J., 73, 106-109.

Whiting, R. B., Powell, W. J., Jr., Dinsmore, R. E., and Sanders, C. A. (1971). Idiopathic hypertrophic subaortic stenosis in the elderly. New Engl.J. Men., 285, 196-200. 